\title{
ENGLISH FOR SPECIFIC PURPOSES: COLLEGE STUDENTS PROCLIVITY AND DISPOSITIONS
}

\author{
K. Pavan Kumar \\ Research Scholar, \\ Department of English, \\ K.L.University, \\ Vaddeswaram, \\ E mail: pkolaganti@gmail.com
}

\author{
Dr. G.Mohana Charyulu \\ Associate Professor, \\ Department of English, \\ K.L.University, \\ Vaddeswaram, \\ Email:gmcharyulu.g@gmail.com
}

\begin{abstract}
Now-a-days English is the best medium of communication throughout the world. It is highly challenging to the English Teachers to face professional decisions in imparting qualitative language teaching. My paper projects certain issues related to college students' likes and dislikes for methodology of learning English Language. I also place importance of skill that is placed on various language skills like LSRW for better communication. It aims at finding the ways to improve the quality of Language teaching and learning. The case studies I present here strive to make changes in learning English among Engineering Students and develop their communicative language with peer groups. I hope the result of these case studies help language teachers to know innovative methods of inspiring learners to standard learning.
\end{abstract}

Keywords: Communicative Language Teaching, qualitative language teaching, likes and dislikes, case studies, Engineering Students, innovative methods, improving standards.

Language is not a subject like Mathematics, Physics, and chemistry and so on. It is a skill rather than a subject to learn and communicate. Communication is not curriculum based learning. It depends on surroundings and situations. It is natural phenomena to transfer information through sounds, gestures, movements and in so many other ways. Medium of Communication depends on individual way of expressions. At this juncture, the role of language teacher is very critical and crucial. It is the method of language teachers to adopt their own professional decisions while ensuring effective language teaching. Effective Language Teaching involves learner centeredness, learning centeredness, and Communicative Language Teaching (CLT). Generally every language teacher knows that the essence of teaching is learner based but not on the stuff of the teacher. Active involvement of the learner in their learning process is called as Learner-centeredness where as learning centeredness means that the learners are able to decide what and how to learn. CLT includes real communication bringing out valuable tasks 
ELK

Asia Pacific Journals

and meaningful teaching methods to the learners. During the time of teaching, the teachers adopt various methods of instruction which depend on various factors. The factors may be like the goals of language course, the needs of the individual learner, learner methodological preferences, proclivity and dispositions of the learners.

This paper presents the proclivity and dispositions of the language learners in learning a foreign language. It also exposes the importance of proficiency that is placed on various language skills. First I gathered information from the students in the Engineering College by making informed decisions to ensure effective language learning. Number of studies on language learning reveals that the attitude of the learner is the predominant factor in effectively learning a language. Language learning attitude of the students of Technical Universities are different from other Engineering Colleges. The opinions and suggestions made by the students are quite unique because students who joined in this institution are different social and economical backgrounds. Psychologists opine that the parental background
ELK Asia Pacific Journals - Special Issue

ISBN: 978-81-930411-1-6

influences the attitude of an individual.

But here the situation is quite different.

Though the parents are highly educated and sophisticated in providing all the essential elements to the students, the students taste and attitude towards learning is quite different. For example, when teachers communicate the parents about the progress and result of the ward, generally they say that the best remedy for the students' improvement is giving homework. In a survey, it is resulted that $60 \%$ of students are not in favour of doing homework as far as English Language is concerned. They argue that language is not a subject like mathematics and physics to be learnt, it is a skill to be acquired through practice. More exercises on language practice in Computer Aided Language Lab are to be conducted through different Presentations, Group Discussions, Debate and Play way method.

Each language teacher has to make professional decisions to ensure effective language learning. Several key concepts with an influence on effective language learning include learner-centeredness, learning-centeredness and communicative language teaching. Learner-centeredness 
Asia Pacific Journals

means active involvement of learners in their learning processes. Learningcenteredness means that learners are able to decide what and how to learn. Communicative language teaching involves real communication - carrying out meaningful tasks and teaching meaningful (to the learner) language. Teachers decisions made during language instruction depend on various factors, the most important of which are the goals of a language course, the needs of the individual learner as well as learner methodological preferences and attitudes to the importance of various language skills. The investigation aimed at gathering such data from students in the college of engineering and making informed decisions to ensure effective language learning.

\section{$\underline{\text { Research Statistics }}$}

The learner's methodological preferences for learning English for Specific Purposes (ESP) were examined using a slightly modified questionnaire described in the reference. There were 56 respondents to this questionnaire who by the time of administering the same. The learners' responses to 7 questions on their learning attitudes are presented. The responses to the first question on homework do not vary much: 50 per cent of learners support the idea of homework against 50 per cent who reject it as shown in Figure 1. It is noteworthy that basically the weakest students dislike the idea of doing homework.

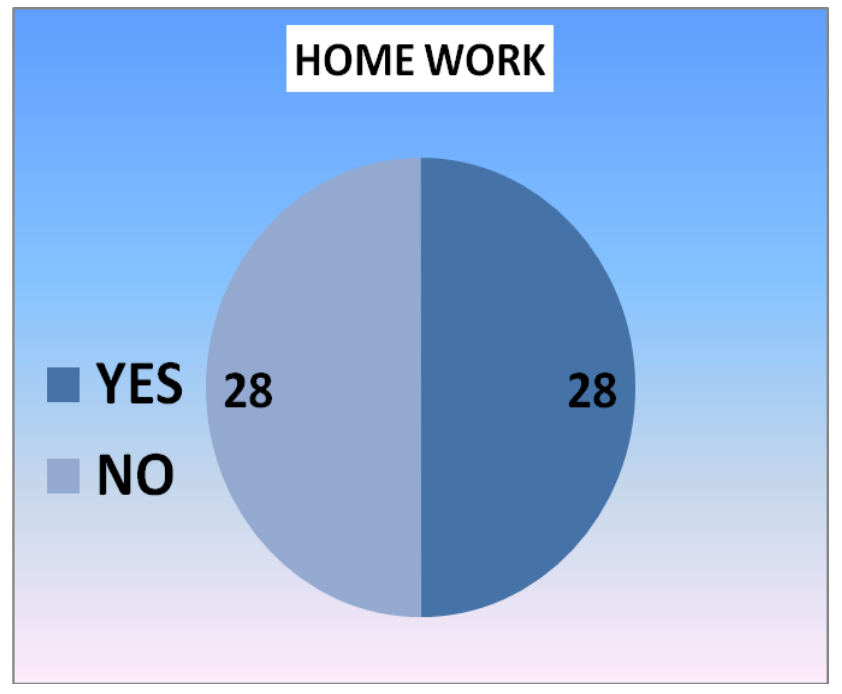

Figure 1

The amount of time spent on homework varies from meager half an hour to extreme 7 hours a week. The percentage is presented under the bar chart and can be summarized as follows. Generally speaking, 80 percentages of learners spend between 1 and 3 hours a week doing their homework: --percentages - 1 hour, -percentages - 2 hours, and -- percentages 3 hours. Only two students, which make just -- percentages, need either 0.5 hour or 
7 hours to do their homework. The individual analysis of data revealed the tendency of slow learners and under- achievers to spend fewer hours on homework while fast learners spend more time on it.

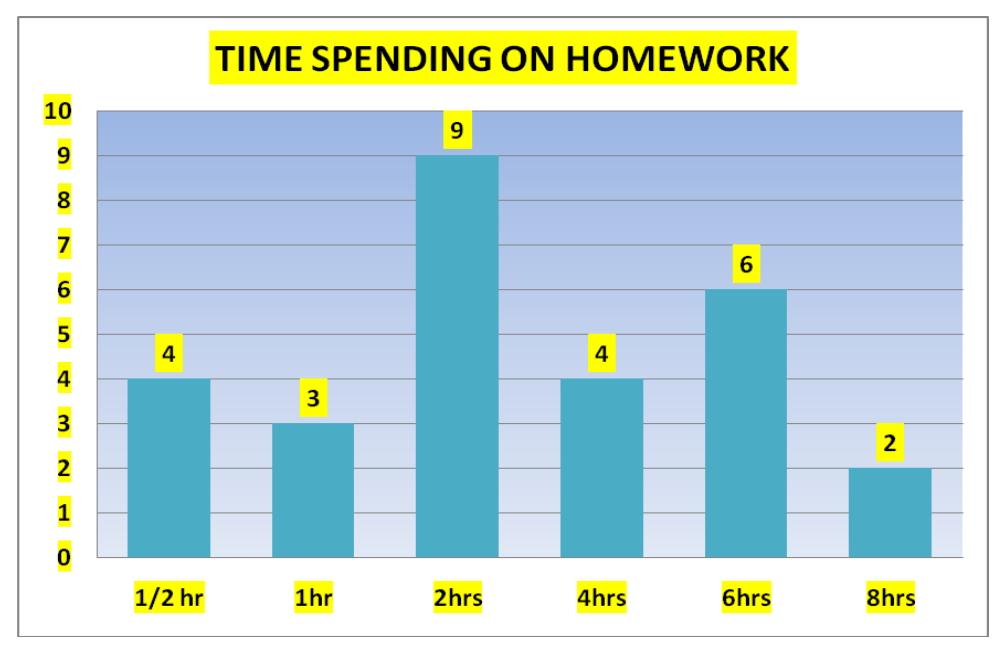

\section{Figure 2}

While asking questions about method of learning, out of 56, 25 students opined to learn through gathering information, and 14 students expressed their opinion by listening to lectures and software. Only one person opted for reading and taking notes as a method of learning. The Figure 3 shows the options of the students.

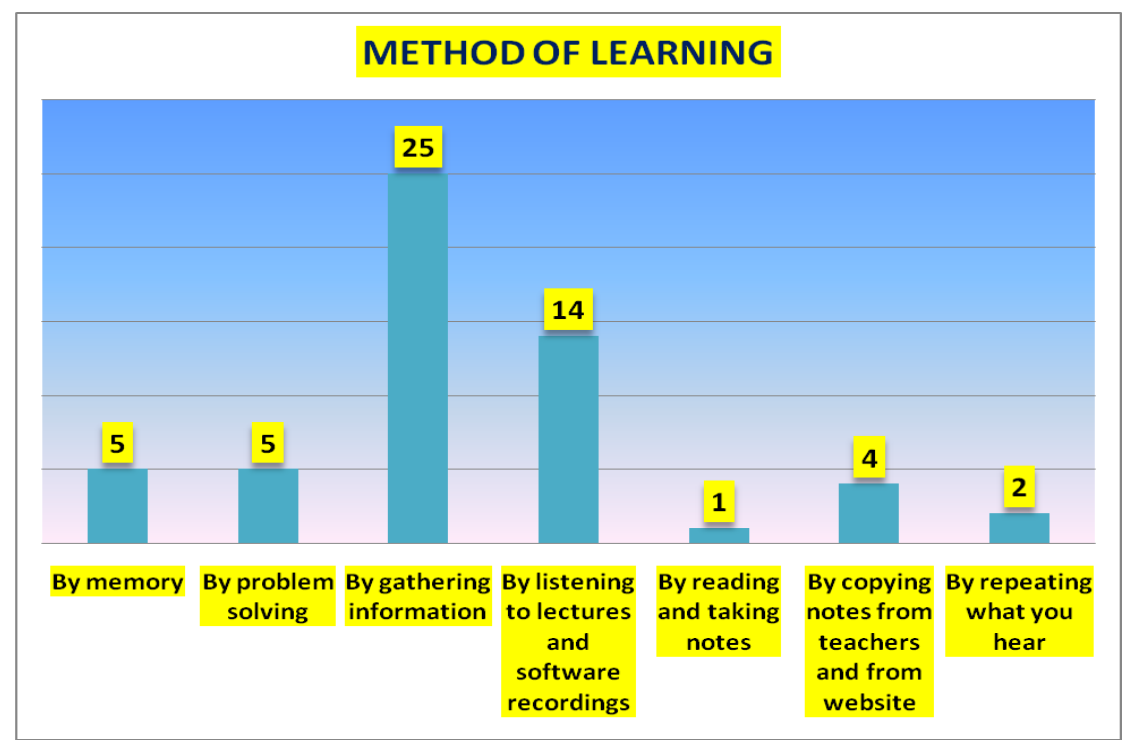

Figure 3 
ELK

Asia Pacific Journals

When the task comes to view of the student about his learning, the question is to correct immediately infront of everybody, or later at the end of the class, or later discussing personally with teacher or friends. The majority of the students stated that they wanted to be corrected
ELK Asia Pacific Journals - Special Issue

ISBN: 978-81-930411-1-6

their mistakes personally discussing with the teachers or friends. Only a few students interested to correct them in the class room itself.

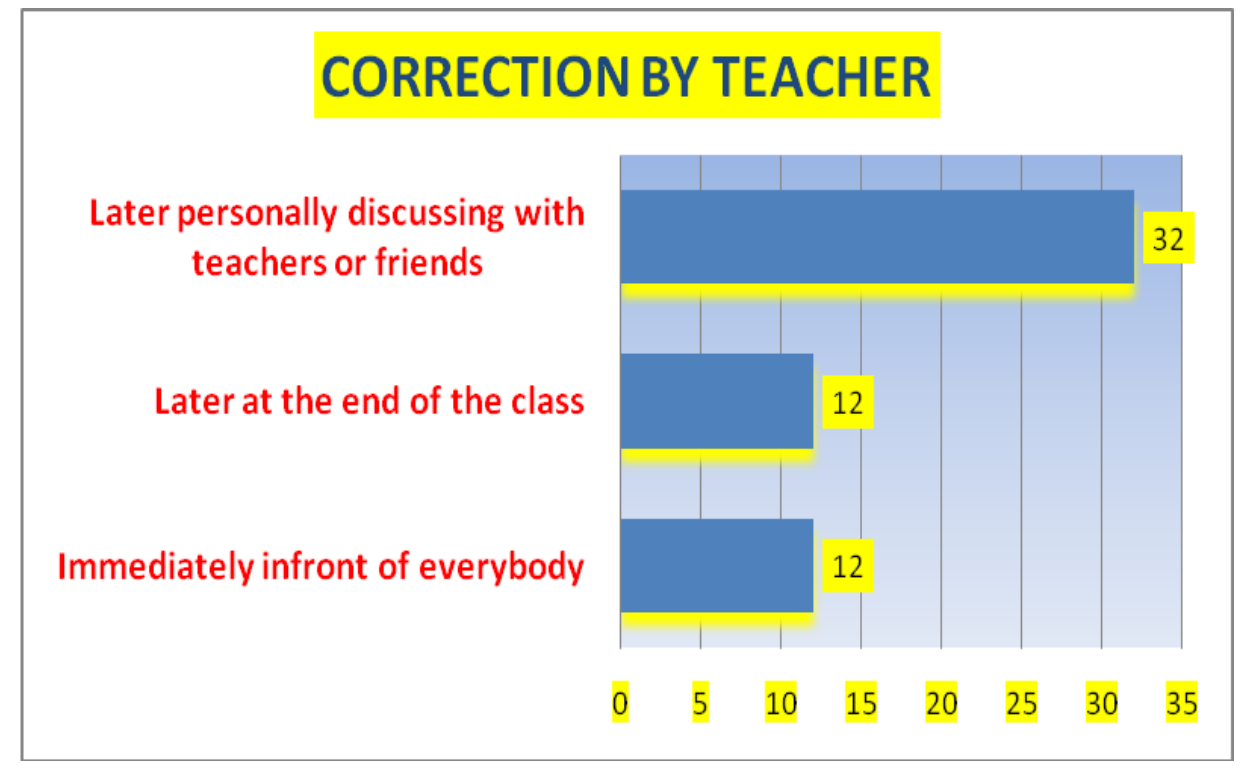

Figure 4

As a part of Task based learning activity, the question of comfortability in Language learning comprises of many actvities. Among them most of the Engineering colleges introduce roleplays and language games. According to the survery conducted it is learnt that out of 56 students 11 students opted for talking and listening to others. There were no students interested in writing summeries. Surprisingly in Andhra Pradesh curriculam designers of APSCHE and School Education prescribe writing summeries as the core essence of their language learning. Majority of the students are interested language games and role plays. 


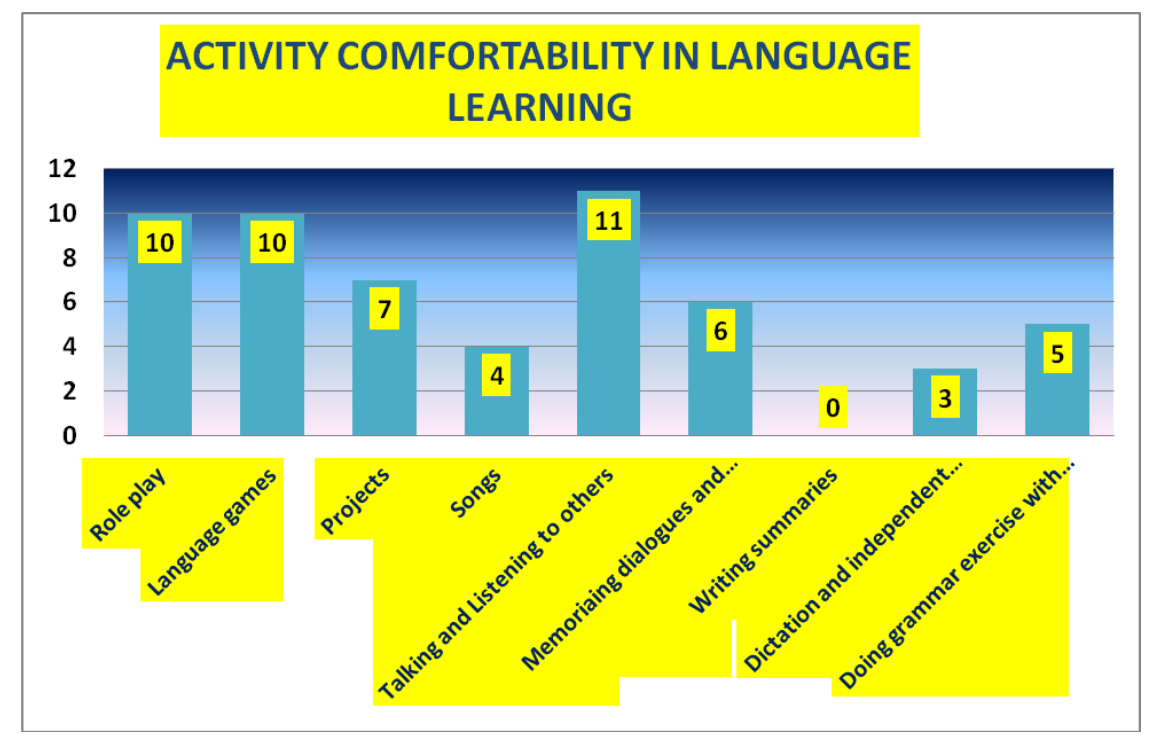

Figure 5

These studies reveal that the majority of the educated Indian speakers of English prefer to use their own unique variety. The importance of proficiency in different aspects of language was examined by administering a questionnaire similar to the one described in and suitably modified to our settings. Three ranking preferences unimportant, important and essential were offered as assessment of proficiency significance. The learner responses are presented in percentage given below in Figure 6.

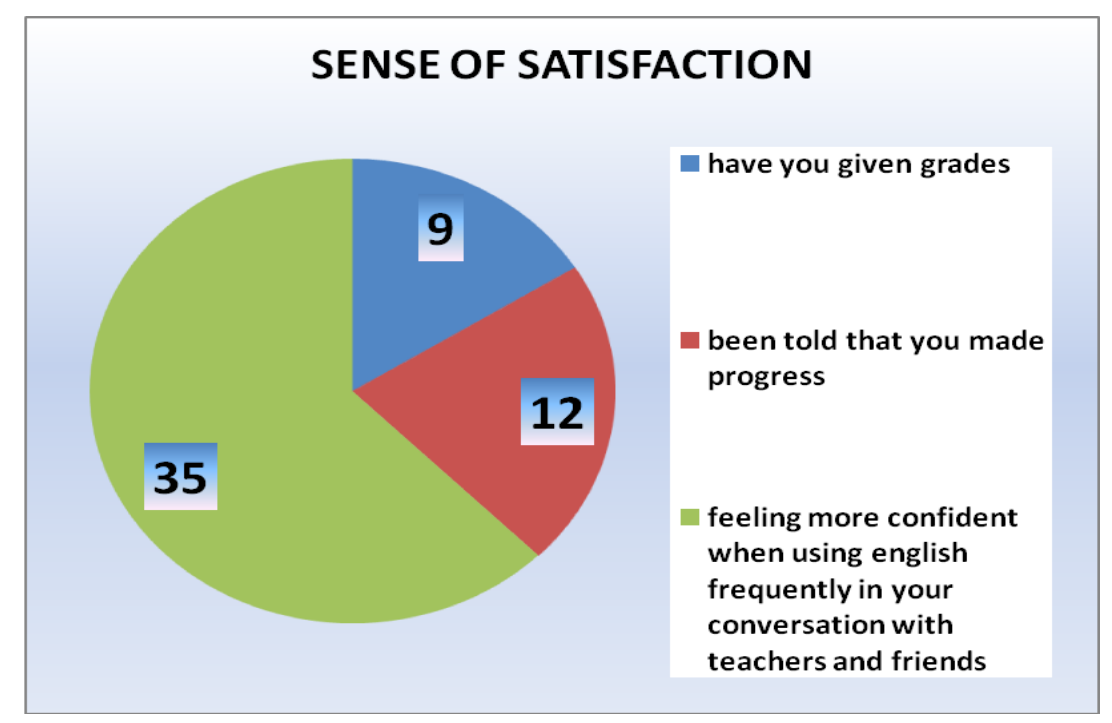

Figure 6 


\section{ELK}

Asia Pacific Journals

Percentage is considered as a more tangible way of presenting statistical data. To simplify comprehension of data given in the Figure 6, the summary of prevailing preferences is provided in the Figure 7.
ELK Asia Pacific Journals - Special Issue

ISBN: 978-81-930411-1-6

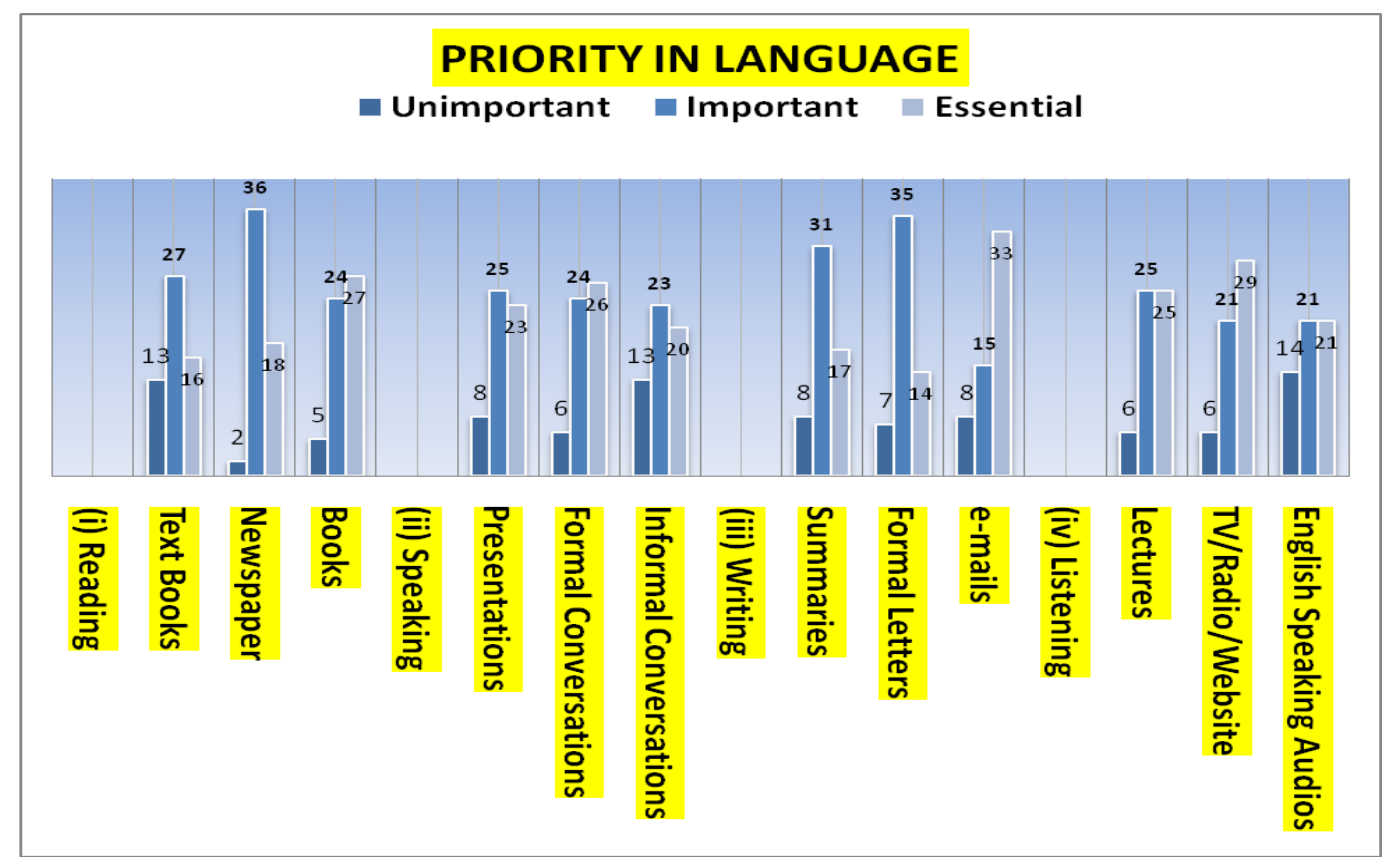

Figure 7

\section{Conclusion:}

Three main conclusions can be drawn from this research. First, slightly more than half of the learners favour a communicative approach to perfecting their language skills by working in pairs / small groups, taking part in projects and practicing English by talking to their peers. Second, given assignments $65 \%$ of learners prefer getting information themselves, listening to
Learner's responses have been ranked in the order of chosen priorities and by adding important, unimportant and essential scores. 
Asia Pacific Journals

class, and to incorporate activities that learners prefer.

\section{References:}

[1] Padwick A (2010). Attitude towards English and Varieties of English in Globalizing India.

[2] Shuib M (2009). Motivation and Attitudes towards learning English.

[3] Data from the students of Engineering College, Vijayawada. 